\title{
Bronchodilation test in COPD: effect of inspiratory manoeuvre preceding forced expiration
}

\author{
P. Santus*, M. Pecchiari", P. Carlucci ${ }^{\oplus}$, B. Boveri*, F. Di Marco*, F. Castagna*, S. Centanni*
}

Bronchodilation test in COPD: effect of inspiratory manoeuvre preceding forced expiration. P. Santus, M. Pecchiari, P. Carlucci, B. Boveri, F. Di Marco, F. Castagna, S. Centanni. (C) ERS Journals Ltd 2003.

ABSTRACT: The effects of an inspiratory manoeuvre preceding forced expiration on functional tests performed under routine conditions before and after inhalation of a bronchodilator drug (salbutamol) were assessed on 150 consecutive chronic obstructive pulmonary disease outpatients. The patients performed forced vital capacity manoeuvres either immediately after a rapid inspiration (manoeuvre no. 1) or after a slow inspiration with a 4-6 s pause (manoeuvre no. 2 ).

Under baseline conditions, forced expiratory volume in one second (FEV1) values were $8 \%$ (\% control) larger with manoeuvre no. 1 than no. 2 . FEV1 values increased with salbutamol administration by $\sim 8 \%$ and were, on average, still $7 \%$ larger with manoeuvre no. 1 than no. 2. The incidence of reversibility, assessed according to American Thoracic Society criteria, was $76 \%$ when manoeuvre no. 2 was selected to represent baseline conditions and manoeuvre no. 1 was chosen to represent the effects of bronchodilator administration, whereas the lowest incidence $(2 \%)$ was found when manoeuvre no. 1 was selected to represent baseline conditions and manoeuvre no. 2 was chosen to represent the effects of bronchodilator administration.

These results indicate that the time dependence of the forced vital capacity manoeuvre has an important impact on the assessment of routine lung function in a clinical setting and supports the notion that the time course of the inspiration preceding the forced vital capacity manoeuvre should be standardised.

Eur Respir J 2003; 21: 82-85.
*Institute of Lung Disease, Respiratory Unit, San Paolo Hospital, "\#nstitute of Human Physiology I, and "Institute of Lung Disease, Policlinico Hospital IRCCS, University of Milan, Milan, Italy.

Correspondence: S. Centanni

Respiratory Unit

San Paolo Hospital

Via A. di Rudinì, 8

20142 Milano

Italy

Fax: 390289123960

E-mail: stefano.centanni@unimi.it

Keywords: Diagnosis

functional testing

spirometry

standardisation

treatment

Received: June 192002

Accepted after revision: September 11 2002
The forced vital capacity (FVC) manoeuvre is the most common ventilatory function test in clinical practice and is used both as a screening test and as a test to diagnose and follow-up pulmonary and extrapulmonary respiratory diseases. In particular, the forced expiratory volume in one second (FEV1) is considered to be the most reproducible respiratory function test. The procedure of FVC measurement and its reproducibility have been described in detail previously [1-3]. In the early 1990s, D' ANGELO and coworkers $[4,5]$ showed that FEV1, peak expiratory flow (PEF) and the forced expiratory flow at 25, 50 and $75 \%$ of $\mathrm{FVC}$ both in healthy subjects and in chronic obstructive pulmonary disease (COPD) patients, are affected by the speed of the inspiration and duration of the end-inspiratory pause before the forced expiration. In particular, FEV1 was found to be, on average, 5 and $8 \%$ higher in healthy subjects and COPD patients, respectively, when FVC was performed immediately after a rapid inspiration rather than a slow inspiration with an end-inspiratory pause of 4-6 s. Therefore, the suggestion was made that a more precise standardisation of the FVC manoeuvre was required.

The purpose of the present study was to assess how the execution of the FVC manoeuvre could affect functional tests performed in everyday clinical practice (i.e. under routine conditions) and to verify the reproducibility of previous results obtained in a small number of COPD subjects after pharmacological bronchodilation with an inhalatory $\beta_{2}$-agonist [6] on a larger COPD population.

\section{Methods}

A total of 150 consecutive caucasian COPD outpatients, referred to the Respiratory Unit, San Paolo Hospital, Milan, Italy, who met the American Thoracic Society (ATS) criteria for COPD diagnosis and care [7], were recruited. The sample comprised 123 males and 27 females aged $66 \pm 7$ yrs, of whom $22 \%$ were still smokers. Informed consent was obtained from all patients. No information was provided about the specific purpose of the study.

A constant-volume body plethysmograph (MasterScreen Body; Jaeger GmBH, Hoechberg, Germany) was used to measure FVC, FEV1, forced expiratory flow (FEFs) and maximum mid-expiratory flow (MMEF), which were corrected for body temperature and ambient pressure and saturated with water vapour. The plethysmograph was equipped with a flow generator, to calibrate 
Table 1. - Anthropometric and routine lung function data for 150 chronic obstructive pulmonary disease patients

\begin{tabular}{lc}
\hline M:F & $123: 27$ \\
Age yrs & $66 \pm 7$ \\
Weight kg & $69 \pm 18$ \\
Height cm & $163 \pm 15$ \\
FEV 1 L & $1.54 \pm 0.56(54 \pm 15)$ \\
FVC L & $2.91 \pm 0.61(65.2 \pm 16.4)$ \\
PEF L $\cdot \mathrm{s}^{-1}$ & $3.05 \pm 1.06(38 \pm 14)$ \\
MMEF L $\cdot \mathrm{s}^{-1}$ & $0.78 \pm 0.48(21 \pm 9)$ \\
TLC L & $5.89 \pm 1.54(104 \pm 25)$ \\
RV L & $2.99 \pm 1.01(148 \pm 50)$ \\
\hline
\end{tabular}

Data are presented as mean \pm SD (\% predicted). FEV1: forced expiratory volume in one second; FVC: forced vital capacity; PEF: peak expiratory flow; MMEF: maximum midexpiratory flow; TLC: total lung capacity; RV: residual volume.

the Fleisch pneumotachograph, and a 30-50 mL syringe to calibrate box pressure [8-10]. Mean group antropometric and routine pulmonary function data are reported in table 1. The predicted values for lung volumes and flows are taken from QUANJER [11].

\section{Methods}

Each patient was requested to discontinue all bronchodilating medications starting from at least $24 \mathrm{~h}$ before execution of the test [12-14]. All subjects performed two types of manoeuvres: no. 1) forced expirations were performed after a rapid inspiration without an end-inspiratory pause; and no. 2) FVC manoeuvres were performed after a slow inspiration with an endinspiratory pause lasting 4-6 s. No instructions were given by the experimenter during the performance of the manoeuvres except for urging the subjects to continue to exhale as long as possible. All manoeuvres were initiated from resting end-expiratory lung volume and were performed in a random order at a comfortable frequency of one every 3-4 min. A number of factors were considered in order to minimise intermanoeuvre variations as follows: 1) the neck was maintained fixed in a neutral position [15]; 2) the expiratory duration was kept similar in the various tests; and 3) all manoeuvres were recorded at similar times during the day. FVC manoeuvres were executed both under baseline conditions and $20 \mathrm{~min}$ after the inhalation of $200 \mathrm{mcg}$ of salbutamol [16, 17], administered with a suitable device (Fluspacer®); Menarini S.r.l., Florence,
Italy). All recorded manoeuvres were divided into four groups: manoeuvre no. 1 under baseline conditions (no. 1B); manoeuvre no. 2 under baseline conditions (no. 2B); manoeuvre no. 1 after bronchodilation (no. 1A); and manoeuvre no. 2 after bronchodilation (no. 2A). A total of 1,800 tests, out of 2,356 tests, met recognised acceptability and reproducibility criteria [3, 18], and three tests were selected for each patient and group.

\section{Analysis}

For each group (no. 1B, no. 1A, no. 2B and no. 2A), the highest value of FEV1, and the values of MMEF and FEF25, FEF50 and FEF75 pertaining to the manoeuvre with the largest value of $\mathrm{FEV} 1+\mathrm{FVC}$ were chosen for the aggregate analysis of all 150 patients [19]. For the assessment of intrapatient differences, the mean of the three tests in each group was used. Data are presented as means \pm SD. Comparisons among experimental conditions were performed using oneway analysis of variance (ANOVA). When significant differences were found, the Bonferroni's correction was introduced to determine significant differences between different experimental conditions. The level of statistical significance was taken at $p \leqslant 0.05$ [20].

\section{Results}

Under baseline conditions, all patients exhibited higher FEV1 values with manoeuvre no. 1 than no. 2 (table 2): on average, the increase of FEV1 was 114士 $54 \mathrm{~mL}$ or $9.1 \pm 4.9 \%$. Relative to predicted FEV 1 values, this increase amounted to $4.3 \pm 2.1 \%$. Similarly, all FEF values were significantly higher with manoeuvre no. 1 than no. 2 (table 2). On an individual basis, FEF25 was larger with manoeuvre no. 1 in 138 patients, FEF50 and FEF75 in 137 patients and MMEF in all patients.

After bronchodilator administration, all patients still exhibited higher FEV1, FEFs and MMEF values with manoeuvre no. 1 than no. 2 (table 2). On average, the increase of FEV1 was $114 \pm 58 \mathrm{~mL}$ or $8.7 \pm 6.6 \%$. Relative to predicted FEV1 values, this increase amounted to $4.2 \pm 2.2 \%$. On an individual basis, FEF25 and FEF75 were larger with manoeuvre no. 1 in 145 patients, FEF50 in 148 patients and MMEF in 141 patients.

The incidence of reversibility, assessed according to

Table 2. - Forced expiratory volume in one second (FEV 1 ), forced expiratory flows (FEFs) and maximum midexpiratory flow (MMEF) during manoeuvres no. 1 and no. 2 under baseline conditions $(B)$ and after bronchodilation test $(A)$

\begin{tabular}{lcccrrc}
\hline Manoeuvre & No. 1B & No. 2B & Change from no. 2B & No. 1A & No. 2A & Change from no. 2A \\
\hline FEV1 L & $1.5 \pm 0.51$ & $1.38 \pm 0.5$ & $9.12 \pm 4.93$ & $1.61 \pm 0.53$ & $1.5 \pm 0.51$ & $8.72 \pm 6.64$ \\
FEF25 L $\cdot \mathrm{s}^{-1}$ & $2.37 \pm 2.01$ & $1.92 \pm 1.73$ & $25.75 \pm 21.18$ & $3.04 \pm 2.46$ & $2.44 \pm 2.01$ & $25.55 \pm 20.81$ \\
FEF50 L $\cdot \mathrm{s}^{-1}$ & $0.96 \pm 0.75$ & $0.83 \pm 0.7$ & $17.03 \pm 15.57$ & $1.25 \pm 1.02$ & $1.09 \pm 0.92$ & $16.59 \pm 12.32$ \\
FEF75 $\cdot \mathrm{s}^{-1}$ & $0.31 \pm 0.22$ & $0.27 \pm 0.18$ & $17.79 \pm 11.93$ & $0.4 \pm 0.31$ & $0.34 \pm 0.25$ & $17.22 \pm 13.97$ \\
MMEF L $\cdot \mathrm{s}^{-1}$ & $0.75 \pm 0.51$ & $0.63 \pm 0.44$ & $19.37 \pm 11.19$ & $0.93 \pm 0.63$ & $0.8 \pm 0.57$ & $18.99 \pm 11.45$ \\
\hline
\end{tabular}

Data are presented as mean \pm SD. All changes from manoeuvre no. 2 are significant $(\mathrm{p}<0.001)$. 
ATS standards [3], depended on the combination of FVC manoeuvres used for this evaluation. The largest incidence of reversible patients $(76 \%)$ occurred when manoeuvre no. 2 was selected to represent baseline conditions and FEV1 with manoeuvre no. 1 was chosen to represent the effects of bronchodilator administration, i.e. (no. $1 \mathrm{~A}-$ no. $2 \mathrm{~B}$ )/no. $2 \mathrm{~B}$, whereas the lowest incidence $(2 \%)$ was found when manoeuvre no. 1 was selected to represent baseline conditions and FEV1 with manoeuvre no. 2 was chosen to represent the effects of bronchodilator administration, i.e. (no. 2A-no. 1B)/ no. 1B. Conversely, intermediate and essentially similar values of the incidence of reversibility were found when the data obtained with the same type of FVC manoeuvre before and after bronchodilator administration were used for the computation. The index of reversibility was larger and similar for both (no. 1Ano. $2 \mathrm{~B}) /$ no. $2 \mathrm{~B}$ and (no. $1 \mathrm{~A}$-no. $1 \mathrm{~B}$ )/no. $1 \mathrm{~B}$, intermediate for (no. 2A-no. 2B)/no. 2B and lower for the last combination.

\section{Discussion}

In this study the authors focused on assessment of FEV1 and FEFs under baseline conditions and after bronchodilation test, as they are the main functional parameters used in clinical practice. The values of FEV1, FEFs and MMEF were found to be systematically higher with manoeuvre no. 1 than no. 2 and these differences persisted after administration of an inhalatory $\beta_{2}$-agonist (table 2 ). These results, when compared to those obtained in the laboratory on normal subjects and COPD patients [4, 5], indicate that the dependence of maximal flow volume curves on the volume-time course preceding the FVC manoeuvre manifests itself in a similar manner in the clinical setting under routine conditions.

Several mechanisms could be responsible for the higher maximal expiratory flows during manoeuvre no. 1 than manoeuvre no. 2 , both in normal subjects and COPD patients [5]. The fact that the relative change in FEV1, as well as in FEFs and MMEF, between manoeuvres no. 1 and no. 2 was essentially the same under baseline conditions and after salbutamol administration (table 2) suggests that the time dependence of these parameters is not related to time constant inequality or the balance between airway and lung tissue hysteresis, which are expected to change with changes the bronchomotor tone. Reduced expiratory effort and dependent volume compression artefacts are also unlikely explanations for the lower flows observed with manoeuvre no. 2 . Indeed, it has been shown that even substantial differences in apparently maximal voluntary expiratory efforts play little or no role in COPD patients [5] and time dependency of FVC manoeuvres is also observed when lung volume changes are assessed plethysmographically $[4,5]$. The present results, in line with previous findings $[4,6]$, suggest that loss of elastic recoil during breath-holding at full inspiration, i.e. stress relaxation, could be the main cause of reduced FEV1, FEFs and MMEF with manoeuvre no. 2. As a result of tissue viscoelastic properties, larger elastic recoil pressures of both lung and chest wall must in fact develop after a rapid inspiration with no end-inspiratory pause; this would provide greater driving pressures, lower airway resistance and hence higher flows during the subsequent expiratory effort.

According to ATS recommended criteria for the response to bronchodilator drugs [7], a 12\% increase in FEV1 relative to baseline value, coupled to an absolute
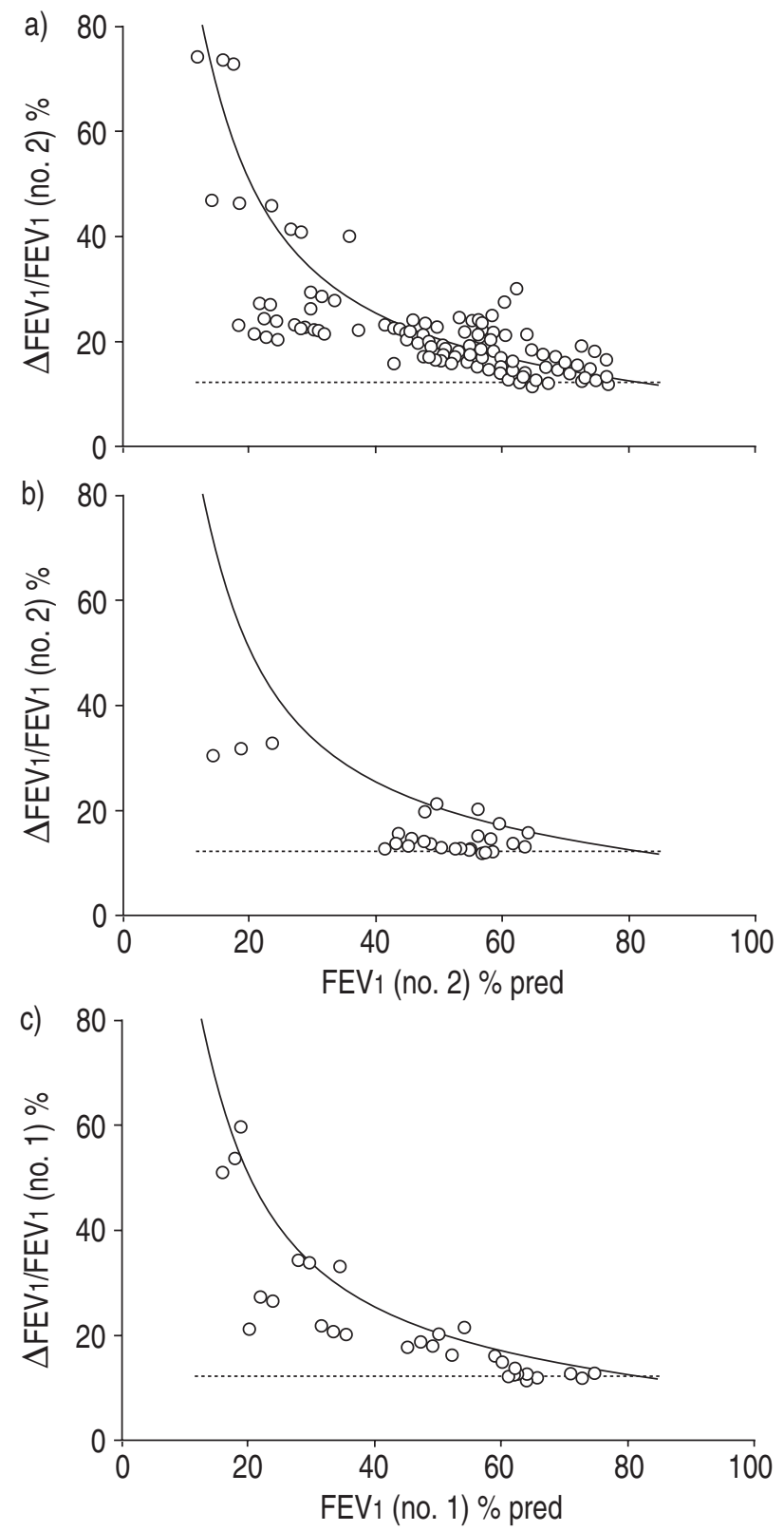

Fig. 1.- Differences between forced expiratory volume (FEV1) after (A) and before (B) bronchodilator administration expressed as percentage of baseline value $\left(\Delta \mathrm{FEV}_{1} / \mathrm{FEV}_{1}\right)$ as a function of baseline values expressed as $\%$ predicted for three combinations of pre- and postbronchodilator FEV1 values: a) (no. 1A-no. 2B)/ no. $2 \mathrm{~B}$; b) (no. $2 \mathrm{~A}-$ no. $2 \mathrm{~B}) /$ no. $2 \mathrm{~B}$; and c) (no. $1 \mathrm{~A}$-no. $1 \mathrm{~B}) /$ no. $1 \mathrm{~B}$. ..... values below which patients are classified as nonresponders to bronchodilator drugs according to the American Thoracic Society criteria [8]; - : values below which patients are classified as nonresponders to bronchodilator drugs according to the European Respiratory Society [9] criteria. 
increase of $200 \mathrm{~mL}$, is considered as a meaningful response. With these criteria, $20 \%$ of patients would be classified as responders based on manoeuvre no. 1 and a similar number would be obtained based on manoeuvre no. 2 (18\%). Conversely, the incidence of reversible patients changed dramatically between manoeuvre no. 1 and no. 2 with the other two combinations; i.e. if manoeuvre no. 1 was made after bronchodilator administration and manoeuvre no. 2 under baseline conditions $76 \%$ of patients could be classified as responders, whereas with the opposite combination the number would drop to $2 \%$. These observations, which are in line with those performed on a small number of COPD and asthmatic patients in the laboratory $[5,6]$, indicate that FVC manoeuvres before and after bronchodilator administration for the assessment of bronchodilator responsiveness must be made under standardised conditions even in the clinical setting under routine conditions. From a practical point of view, it is important to note that standardisation does not imply the choice of the type of manoeuvre. Indeed assessment of bronchodilator responsiveness with manoeuvre no. 1 yielded essentially the same results obtained with manoeuvre no. 2 .

The criteria for the response to bronchodilator drugs recommended by the European Respiratory Society [17] are more demanding than those indicated by the ATS [7], especially when baseline FEV1 values are low, as shown in figure 1 . Nevertheless, the incidence of reversibility assessed according to ERS standards [19] was still dependent on the combination of FVC manoeuvres used for evaluation, although the number of patients that could be classified as responders was substantially reduced with combinations (no. 2A-no. 2B)/ no. $2 \mathrm{~B}$ or (no. $1 \mathrm{~A}$-no. 1B)/no. $1 \mathrm{~B}$.

In conclusion, the present study performed on 150 chronic obstructive pulmonary disease patients has shown that the time dependence of the forced vital capacity manoeuvre has an important impact on the assessment of routine lung function in the clinical setting, and supports the notion that the time course of the inspiration preceding the forced vital capacity manoeuvre should be standardised. Indeed, bronchodilation tests performed with different manoeuvres before and after bronchodilator administration easily provide misleading results, overestimating a positive response to bronchodilators if manoeuvre no. 2 is used before and manoeuver no. 1 after drug administration, and underestimating it in the opposite case. From a clinical perspective, this could lead to a wrong diagnosis and improper therapy.

Acknowledgements. The authors would like to thank E. D'Angelo for useful and critical review of this manuscript.

\section{References}

1. Gardner RM. Report of snow-bird workshop of standardization of spirometry. ATS news. 1977; 3: 20.

2. American Thoracic Society Statement. Snowbird workshop on standardisation of spirometry. Am Rev Respir Dis 1979; 119: 831-838.

3. American Thoracic Society. Lung function testing: selection of reference values and interpretative strategies. Am Rev Respir Dis 1991; 144: 1202-1218.

4. D'Angelo E, Prandi E, Milic-Emili J. Dependence of maximal flow-volume curves on time course of preceding inspiration. J Appl Physiol 1991; 70: 26022610.

5. D'Angelo E, Prandi E, Marazzini L, Milic-Emili J. Dependence of maximal flow-volume curves on time course of preceding inspiration in patients with chronic obstructive pulmonary disease. Am J Respir Crit Care Med 1994; 150: 1581-1586.

6. D'Angelo E, Milic-Emili J, Marazzini L. Effect of bronchomotor tone and gas density on time dependence of forced expiratory vital capacity maneuver. Am J Respir Crit Care Med 1996; 154: 1318-1322.

7. Standard for the diagnosis and care of patients with chronic obstructive pulmonary disease. Am J Respir Crit Care Med 1995; 152: S78-S121.

8. Sullivan WJ, Peters GM, Enright PL. Pneumotacographs: Theory and clinical applications. Respir Care 1984; 29: 736-739.

9. Nelson SB, Gardner RM, Crapo RO, Jensen RL. Performance evaluation of contemporary spirometers. Chest 1990; 97: 288-297.

10. Finucane KE, Egan BA, Dawson SV. Linearity and frequency response of pneumotachographs. $J$ Appl Physiol 1972; 32: 121-126.

11. Quanjer PhH. Standardized lung function testing. Bull Eur Physiopathol Resp 1983; 19: Suppl. 5, 22-61.

12. Rabe KF, Jorres R, Nowak D. Comparison of the effects of salmeterol and formoterol on airway tone and responsiveness over 24 hours in bronchial asthma. Am Rev Respir Dis 1993; 146: 1156-1160.

13. Cazzola M, Matera MG, Santangelo G, Vinciguerra A, Rossi F, D'Amato G. Salmeterol and formoterol in partially reversible severe chronic obstructive pulmonary disease: a dose-response study. Respir Med 1995; 89: $357-362$.

14. Cazzola M, Santangelo G, Piccolo A. Effect of salmeterol and formoterol in patients with chronic obstructive pulmonary disease. Pulmon Pharmacol 1994; 7: 103-107.

15. Melissinos CG, Mead J. Maximum expiratory flow changes induced by longitudinal tension on trachea in normal subjects. J Appl Physiol 1977; 43: 537-544.

16. Nisar M, Earis JE, Pearson MG, Calverley PMA. Acute bronchodilator trials in chronic obstructive pulmonary disease. Am Rev Respir Dis 1992; 146: 555-559.

17. Siafakas NM, Vermeine P, Pride NB, et al. Optimal assessment and management of chronic obstructive pulmonary disease (COPD). Eur Respir J 1995; 8: $1398-1420$.

18. American Thoracic Society. Standardization of spirometry. Am J Respir Crit Care Med 1995; 152: 1107-1136.

19. Knudson RJ, Lebowitz MD. Maximal mild-expiratory flow (FEF25\%-75\%): normal limits and assessment of sensitivity. Am Rev Respir Dis 1978; 117: 609-610.

20. Snedecor GV, Cochran WG. Statistical methods. 8th Edn. Ames, Iowa State University Press, 1989. 